\title{
SOME PROBLEMS IN THE CONTROL OF INSECTS IN STORED FOODS IN CALIFORNIA
}

\section{R. W. DouNe, Stanford University}

The critical situation in which we find ourselves at the present time, particularly as regards the food that we need for our allies and ourselves, strongly emphasizes the necessity of taking every step possible to prevent the loss of foods or food materials.

The entomologists have been keenly aware of the importance of insects in this struggle for food, and since the very beginning of the war have been trying to bring before those in authority and before the people in general the important facts bearing on this subject. As a rule we have met with a hearty response when we have called for action along certain definite lines, but we have also met with disappointments, for it is sometimes very hard to convince the uninitiated that things as small and lowly and despised as insects can play an important part in this great world war.

But when one finds a mass of flour and excrement matted together by the webbing made by the larvæ of the Mediterranean four moth, or when one finds the dark ill-smelling flour beetles in the flour, or the weevils or their larvæ in the rice or beans or other food products, it is not hard to convince the observer that something is wrong, and all agree that something should be done to correct this disagreeable state of affairs.

Here in California where many insects breed throughout the year, we have paid but little attention to the insect pests of stored foods. Twenty-five years ago Prof. W. G. Johnson, at the time an instructor in Entomology in Stanford University, did a good deal of work with the Mediterranean flour moth in the mills around San Francisco Bay and a little attention has been paid to the larvæ found in stored fruit. But little other work has been done.

In a very hurried survey that we have made of about 100 warehouses and flour mills in Central and Southern California, while acting as consulting entomologist for the Federal Food Commission for California, we have found practically all of the common pests of stored foods in greater or less abundance. The Mediterranean flour moth is found in nearly all of the flour mills and is regarded by all as the most serious pest that we have to deal with in such places. The larvæ spin their silken threads wherever they go, and as they go everywhere, all of the machinery, the elevators and shoots, as well as the flour in the bins and sacks, become covered or filled with masses of webbing which cause no end of trouble for the miller. 
The Mediterranean flour moth is also the most common pest of warehouses. In several instances we have seen hundreds of sacks of flour covered with the fine web that is spun by the larvæ as they wander about seeking a suitable place to pupate. These same sacks would be punctured with holes made by the larvæ as they came out and little heaps of flour on the sack indicated where other larvæ were working. In one warehouse nearly 1,000 sacks were thus seriously infested and about 2,000 other sacks showed only lighter infestation. The most seriously infested lots in the warehouse were those that had been in there for several months but one lot of nearly 500 sacks that had been in the warehouse only two weeks was heavily infested and the larvæ were issuing from the sacks in great numbers. This lot was, of course, badly infested before it came into the warehouse.

Fortunately the conditions in this warehouse were not typical of those found in most of the others visited. In one other instance we found 2,300 sacks of flour quite badly infested, but as a rule only smaller lots were found to be badly infested and in many warehouses we found very little or no infestation.

The rice weevil, Calandra oryza L., was found in great numbers in some warehouses and was present in smaller numbers in many other places. The heaviest infestation was found in a corner of an upper floor of a warehouse that was otherwise in fine condition. The beetles were first noticed crawling over sacks of flour stored near a window. Then it was found that the floor near this window was literally covered with the beetles and many were also found crawling over bags of imported rice in the end of the warehouse.

The source of this trouble was, after a long search, found to be a small, old, and evidently forgotten lot of rice stacked back of a larger lot that quite hid it. The bags were completely covered with the beetles and the floor and nearby bags of rice were also covered with masses of weevils that moved about slowly when the flashlight was turned on them.

In another warehouse little heaps of flour on a number of sacks indicated the presence of some insect. Further examination showed that inside the sack back of each of the little piles of flour, one of these rice weevils was working. A few holes were found showing where the weevils had issued from the sacks and some of them were found crawling about. Three lots of flour in different parts of the warehouse were found to be thus infested. Later it was found that these three lots, representing different brands of flour, had all come from the same mill and the source of the infestation will doubtless be found in the mill. Other lots of rice and a few lots of wheat were found to be infested with this pest. 
The granary weevil, Calandra granaria L., was found in probably half of the warehouses visited, but usually only in small numbers.

The saw-toothed grain beetle, Silvanus surinamensis, is commonly found associated with this species and in some instances they both become very abundant and destructive. One warehouse that had suffered very severely from the attacks of these two pests in 1917, was still badly infested. Certain lots of waste grain and chaff were alive with these beetles and some of the large bins that were filled with barley were badly infested. As some of this barley was being moved from one bin to another it was passed over a screen and the screenings were found to consist largely of these beetles. In another instance all of the corn in a feed store was found to be badly infested with these twio beetles. The confused flour beetles, Tribolium confusum, were found in nearly all warehouses and in some of the mills. Usually they were not present in great enough numbers to be of much importance but in some places they were causing much trouble and loss. They are general feeders, nearly all kinds of food products being attacked.

The rust-red flour beetle, $T$. navale Fab., was also found in a few places. Their presence gives the food a disagreeable, musty odor. Bread made from flour that has been infested with these beetles, has a disagreeable odor when first baked, but this all or nearly all disappears as the bread cools.

A few other moths and beetles, some of them as yet unidentified, and a mite, probably Tyroglyphus longior Ger., have been found in various cereals or cereal products in mills, warehouses, stores and private houses, but no attempt will be made to give a list of these now, as the inspections that we are still making keep bringing to light new and interesting forms.

We have found but a few instances of weevil infestation in 'beans; 'but when these occurred the loss was almost or quite complete. Adults of the third generation are now, March 25, appearing in lots of beans that have been in my laboratory since November.

But the important question of "What can we do about it?" is the chief concern of the miller, the warehouse manager, the storekeeper and the housewife, and of course therein lies our chief interest in these investigations.

Preventive measures are usually of first importance in dealing with any insect. In the case of these pests, particularly, too much emphasis cannot be placed on the importance of cleanliness and a careful watch of all incoming material.

Cleanliness will not always insure freedom from attack by the insect pests of stored products, but, in spite of certain notable exceptions, the rule holds that the amount and extent of the infestation bears a very 
close relation to the degree of cleanliness about the mill or warehouse or store-room. Some of the best mills keep their machinery and floors and walls quite free from flour dust by using compressed air for cleaning out the cracks and crevices, blowing the dust out where it can be easily swept up by brooms. Others make a practice of treating their floors at regular intervals with gasoline or kerosene to destroy the lar$\mathrm{v} \mathfrak{x}$ and beetles and mites that accumulate in the cracks in all but the very best of floors.

light is always a great factor in cleanliness and modern mills and warehouses are now built so that all parts of the house may be well lighted and of course daylight is preferable to any kind of artificial light. The claim is sometimes made that insects will not breed in food materials that are stood in light places. While it is true that insect pests are usually less common in such places, the rule is not a safe one in practice, for light does not altogether protect foods from infestation. Indeed, it seems that, while as a rule these insects prefer to work in dark places, they may under certain conditions, probably at breeding time, seek out the light. I have already referred to the swarms of rice weevils that had gathered to the light near a window, when the infested material from which they came, was near the middle of a long room with light only at the ends. Many other instances might be cited where not only the weevils but the moth larvæ were found in material stored in places where the light was good and strong.

Given a good, clean, light warehouse or mill, the careful manager will watch with unceasing vigilance everything that comes into his house. There are certain signs that usually betray the presence of insects to the careful observer, even when the food material is packed in sacks and boxes, and if there is any reason whatever for believing that incoming goods are infested, a careful examination must be made. Used sacks are particularly dangerous sources of infestation and should always be looked on with suspicion and thoroughly cleaned or fumigated before being admitted to the storeroom.

But in spite of all our care, infested materials may be carried into even the cleanest of places, or the adult insects themselves may fly or crawl in. In the same way some of the most important insect pests of our farms and orchards have escaped the watchful eye of the quarantine officer, and in both instances active control measures soon become necessary.

In a clean well lighted place, it is usually easy to detect the beginnings of an infestation which may be checked before it has spread far, but which, if left alone, would soon become of much more importance. A lightly infested lot of flour or meal may be sifted or rebolted and put in clean sacks with but little loss if the material is in a mill or can be 
sent to one. If it is not possible to attend to this at once, or if it is necessary to move the infested material from one place to another, it is worth while to first clean the outsides of the sacks or other containers, in order that the insects may not be spread about in the moving.

The managers of some mills believe they have taken sufficient precautions to prevent the spread of the Mediterranean flour moth when they place infested lots of flour some distance away from other flour. One warehouse man told me that when he found any food stuffs infested with insects he always put a ring of hydrated lime around the infested lot to prevent the spread of the pest to other parts of the house. Another man was found to be using formaldehyde for fumigating a room badly infested with rice weevils and he could not understand why the beetles kept spreading.

Such "protective" measures are dangerous, not only because they do not kill the insects, but because they either give the experimenter a false sense of security or else he becomes discouraged and gives up altogether.

It is an easy matter for us to carry on a series of experiments with these insects, and to find that under certain conditions, that we have well under control, we can kill all or nearly all of the pests with which we are working. But as soon as we get out into the warehouses and mills, we begin to meet with serious difficulties. Let me give a concrete example: The warehoùse previously referred to, where 2,000 or 3,000 sacks of infested flour was found, also had about 20,000 other sacks that were infested very lightly or not at all. This flour belonged to some twenty-seven different owners and was scattered throughout the warehouse. Stored with the flour, or close to it, was to be found many other kinds of food stuffs. Some of the owners of the flour believed that the warehouseman should fumigate his house and kill the insects, others objected because they were afraid that the flour or other foods might be injured by being fumigated.

The manager was told that the Board of Underwriters had said that anyone fumigating with carbon bisulphide would do so at his own risk, as his insurance would not cover the risk from fire if he had such materials in his house. On account of the danger to foodstuffs containing a great deal of moisture he could not use cyanide and the house was not tight enough for fumigating purposes anyway. There was no provision for heating the house by steam or otherwise. What should the poor man do? While he was seeking an answer to this question, the condition of the badly infested flour was called to the attention of the Pure Food Inspectors of the Bureau of Chemistry. They ruled that much of it was unfit for human food and the owners agreed to sell the most of it for stock food or for making paste for bill-posting purposes, and to reprocess the rest and thus save as much as possible. 
This is only one, fortunately the worst one, of many troublesome cases we have had to deal with since beginning these inspections. As long as the insurance men refuse to take the fire risk when carbon bisulphide is used, I can only recommend the use of that important insecticide in small detached buildings or in places where no insurance risks would be involved. The managers of some mills and some warehouses tell us that they fumigate regularly with hydrocyanic gas, but often when talking with the foreman of such a place, we find that the work has not been done as often as reported and sometimes we find that it has really not been done at all. So it is very hard to get exact data on the amount of this work that is actually done. Those who are using this gas, or report that they are using it, say that they do not regard it as dangerous in mills or in warehouses where only cereals or cereal products are stored. But the Pure Foods Laboratory of the U. S. Bureau of Chemistry, when asked if there could be any danger from this source, ruled that there might be danger at least when other food products were present in the building.

Mr. De Ong, who has been associated with me in some of this work, planned to make a series of experiments in order that we might know definitely the answer to some of these questions but he is not yet ready to report.

We found only one mill where provision was made for using heat for fumigating. In this mill a small room, about $8 \times 10 \mathrm{ft}$. with a $12 \mathrm{ft}$. ceiling, was provided with a large radiator and the miller told me that. he could easily maintain a temperature there of $130^{\circ}$ to $140^{\circ} \mathrm{F}$. for several hours. In this room he places the infested packages of cereals that are sent back from the wholesalers and the retailers and subjects them to these high temperatures with the result that all the insects are killed. Materials only slightly infested can be reprocessed and the others can be used for stock food and the danger of the insects spreading over the mill is eliminated.

I have strongly recommended the construction of such fumigating rooms in many other mills and in some warehouses, where steam for heating was available. The room for such a purpose need not be a large one for if the lot of material to be treated is more than can be stood in the room at one time, it can be divided into small lots and the process repeated as many times as necessary.

The very interesting and important question as to whether the excretions of the insects, while they are in the flour or other food products, has any harmful effect on the food, keeps coming up constantly. It has been very generally assumed that if the insects can be removed the food will be perfectly wholesome. Few of us, however, can anticipate with any great pleasure the using of flour that has been infested 
with any of these insects, even if it has been sifted or thoroughly rebolted before being used. The ordinary sifting romoves all of the insects, at least all of the larger ones, but it unfortunately does not remove all of the fecal matter. Only rebolting will do this. Some believe that this fecal matter may contain enough poison to affect more or less seriously anyone using such contaminated flour. Others, and among them some prominent chemists and toxicologists, do not think any harm whatever could come from using bread made from even badly infested flour.

I am told that the results of some recent experiments seem to indicate that the poison, if any is present, may be due to the urates of the insects infesting the grain or flour. Cleaning the grain or sifting or even rebolting the flour would not remove the danger from this source, if it really exists.

This seems to be a subject, worthy of further investigation and a chemist and an entomologist working together might be able to obtain some interesting and valuable results.

President G. P. Weldon: This paper by Professor Doane is now open to discussion.

R. E. CAMPBELL: Is the HCN gas collecting in moist fruit products a real or an imaginary danger?

R. W. Donne: There seems to be some claim in fact for such a statement.

G. P. Weldon: How much material is necessary?

R. S. Woglum: Three ounces to 1,000 cubic feet has been recommended in a publication by Chittenden. Experiments carried on some time ago at Kansas Station included analyses and baking qualities of the product after fumigation.

G. P. GrAY: I have gone into the records of the Kansas Station and as I recall there is no definite statement about flour absorbing HCN. While I believe there is no danger, still it is a matter that must be seriously considered.

H. T. Fernald: There would be a difference whether or not the product is cooked after fumigation.

R. E. CAMPBell: It seems to me there is possibility of developing in this connection insect proof containers.

H. J. QUAYLE: I am sorry that I did not hear all of the paper, but it seems to me the question of penetration is important in this connection, and as I understand it carbon bisulphide penetrates such material as grain and the like better than hydrocyanic acid.

G. P. GrAY: The objection on account of danger of using carbon 
bisulphide in warehouses might be overcome by having a special room constructed outside the warehouse.

R. W. Donne: I recommended such a course in the case of a warehouse I visited a few days ago.

President G. P. Weldon: The next paper in order is "Fumigation Experiments: The Time Factor," by A. F. Swain.

\section{FUMIGATION EXPERIMENTS: THE TIME FACTOR}

By A. F. Swaln, University of California, Citrus Experiment Station, Riverside, California

\section{INTRODUCTION}

The control of the insect peste of citrus trees in California is accomplished largely by the use of hydrocyanic acid gas. As practiced at the present time, there is a considerable variety in the methods of procedure, and there are many problems on which further data are desirable. Among these is the determination of the proper time of exposure; whether the times in most common use, namely, 45 and 60 minutes, are the most practical; whether a shorter period would suffice or a longer period be more efficient; and whether there is any real difference in the efficiency between the 45 and 60 minute periods.

While carrying on some fumigation experiments for another purpose during the season of 1916-1917, the writer was impressed by the fact that there did not seem to be any constant and appreciable difference between exposures of 45,50 , and 60 minutes. However, as these experiments were not arranged for the determination of that factor, no certain results could be obtained therefrom. During the past season the problem again came up, and the writer made a few experiments in an attempt to add further data to the question. In this paper are given the results of those experiments, together with the results of actual commercial fumigation, as carried on in 125 groves in Tulare County during July, August and September, 1917, for the control of the citricola scale (Coccus citricola).

\section{Experimental Fumigation}

The necessary apparatusfor the carrying on of these experiments consisted of the following. Two form "trees" of the same size and shape were used. These consisted of frameworks of such form that when covered with a tent they would approximate the shape of a fair-sized orange tree. Each measured 26 feet around by 31 feet over, which size requires, according to the schedules in use at present, a six ounce charge of sodium cyanide for the 100 per cent or full schedule. They were each covered with tents of the same size and material; namely, 